\title{
ANTERIOR HEPATIC TRANSECTION FOR CAUDATE LOBECTOMY
}

\author{
Eleazar Chaib, Marcelo A F Ribeiro Jr, Yngrid Ellyn Dias Maciel de Souza, \\ Luiz Augusto C D'Albuquerque
}

doi: $10.1590 / \mathrm{S} 1807-59322009001100013$

Chaib E, Ribeiro Jr MAF, Maciel de Souza YED, D’Albuquerque LAC. Anterior hepatic transection for caudate lobectomy. Clinics.2009;64(11):1121-5.

Resection of the caudate lobe (segment I- dorsal sector, segment IX- right paracaval region, or both) is often technically difficult due to the lobe's location deep in the hepatic parenchyma and because it is adjacent to the major hepatic vessels (e.g., the left and middle hepatic veins).

A literature search was conducted using Ovid MEDLINE for the terms "caudate lobectomy" and "anterior hepatic transection" (AHT) covering 1992 to 2007.

AHT was used in 110 caudate lobectomies that are discussed in this review. Isolated caudate lobectomy was performed on 28 (25.4\%) patients, with 11 case (11\%) associated with hepatectomy, while $1(0.9 \%)$ was associated with anterior segmentectomy. Complete caudate lobectomy was performed on $82(74.5 \%)$ patients. Hepatocellular carcinoma was observed in $106(96.3 \%)$ patients, while $1(0.9 \%)$ had hemangioma and $3(2.7 \%)$ had metastatic caudate tumors. AHT was used in $108(98.1 \%)$ caudate resections, while AHT associated with a right-sided approach was performed in $2(1.8 \%)$ cases. AHT is recommended for tumors located in the paracaval portion of the caudate lobe (segment IX). AHT is usually a safe and potentially curative surgical option.

KEYWORDS: Liver; Caudate Lobe; Anterior approach; Resection.

\section{INTRODUCTION}

The caudate lobe is located anterior to the inferior vena cava (IVC) and may envelop this structure circumferentially. It extends to the hilum of the liver just posterior to the bifurcation of the portal vein. Cephalad, the caudate lobe lies posterior to the confluence of the left and middle veins as they enter the IVC on the left (Figure 1).

The caudate lobe is generally divided into three regions: the left Spiegel lobe, the process portion, and the paracaval portion. The anatomy of the paracaval portion includes the liver parenchyma ventral to the hepatic IVC and the area between the Spiegel lobe and the right lobe adjacent to the middle hepatic vein ventrally. ${ }^{1}$ This portion was classified by

\footnotetext{
John Radcliffe Hospital, Nuffield Department of Surgery - Oxford, UK. Email: eleazarchaib@yahoo.co.uk Tel: 01865765807

Received for publication on June 23, 2009

Accepted for publication on August 11, 2009
}

\section{Couinaud as segment IX (2).}

Our aim in this study is to describe the standard technique for a caudate lobectomy procedure involving an anterior hepatic transection (AHT) via a review of the literature.

A literature search was conducted using Ovid MEDLINE for the terms "caudate lobectomy" and "AHT" covering 1992 to 2007.

\section{Operative procedure for caudate lobe resection using an AHT}

Resection of the caudate lobe involves three major steps:

(1) Controlling the inflow caudate blood supply from the left portal vein and the left hepatic artery at the base of the umbilical fissure, as well as controlling other inflow by lowering the hilar plate and dividing any vessels encountered;

(2) Dissection of the retrohepatic veins; and

(3) In the case of an isolated caudate resection, it is neces- 


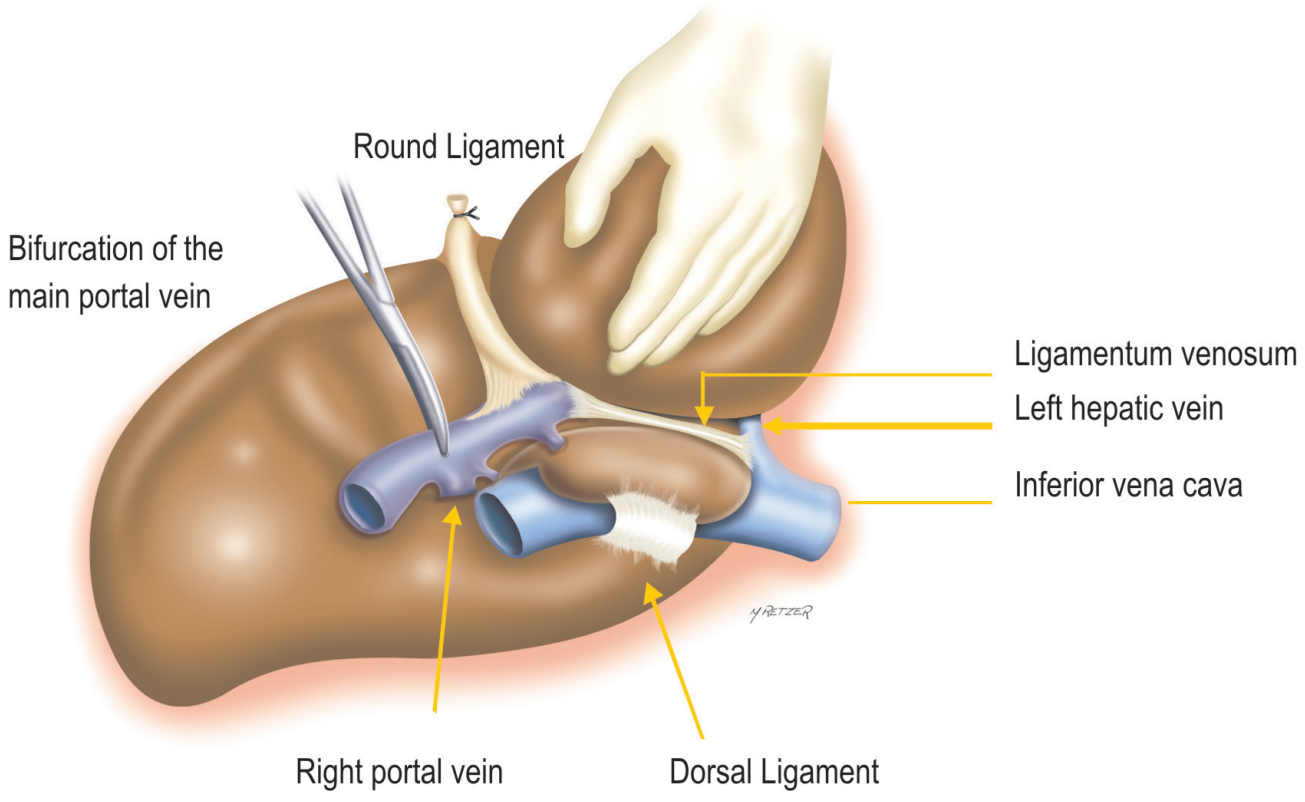

Figure 1 - View of the caudate from the left. Note that the ligamentum venosum is usually called Arantius' ligament

sary to divide the liver parenchyma between the base of segment IV and the left side of segment VII to allow removal of the lobe.

When an AHT of the caudate lobe is used, an anatomic resection of segment I or/and segment IX (an isolated or complete resection of the caudate lobe) may be performed.

Some authors have split the liver anteriorly through the Glissonian plane, separating the right and left liver, and approaching the caudate lobe by dividing the liver along the right margin of segment IV. The combination of these techniques allows for the preservation of middle hepatic venous flow and good control of bleeding.

After cholecystectomy, the right lobe is mobilized from the retroperitoneum, and the IVC is mobilized by ligating and dissecting the short hepatic veins caudocranially. The right hepatic vein (RHV) is secured after division of the vena cava ligament. ${ }^{2}$

On the left side, after dissecting and bending up the lateral segment and dividing the ligamentum venosum (Arantius' duct) at its junction with the left hepatic vein, the Spiegel lobe is separated from the IVC, and the trunk of the left and middle hepatic veins is taped. The liver is completely separated from the IVC except for the major hepatic veins.

Prior to liver transaction, the outer confines of the caudate process and the paracaval portion against the posterior segment are identified using a counterstaining technique. ${ }^{3,4}$ Under the Pringle maneuver (a hepatic inflow occlusion time of 15 minutes and a reperfusion time of 5 minutes), transaction is performed along the left side of the middle hepatic vein (MHV), opening the interlobar plane and exposing the anterior surface of the paracaval portion and the hilar plate.

The paracaval portion is detached from the hilar plate by ligating and dividing the ascending caudate portal branches. The transaction then proceeds in two directions: to the left side toward the sulcus of the ligamentum venosum (Arantius' ligament) and to the right side just behind the MHV.

On the left side, after dividing the ligamentum venosum and the Spiegel branches, the Spiegel lobe is liberated from the left lobe. On the right side, the hilar plate is exposed up to the bifurcation of the anterior and posterior portal pedicles. With the right lobe bent medially, liver transaction is conducted from the border of the posterior segment and the caudate process, exposing the dorsal surface of the RHV. When the liver parenchyma dorsal to the RHV is transected, resection is complete.

\section{RESULTS}

This study analyzed the records of 110 patients who were submitted to caudate lobectomy involving an anterior transhepatic approach between 1990 and 2007, as shown in Table 1. Isolated caudate lobectomy was performed on 28 (25.4\%) patients, while complete caudate lobectomy was carried out on $82(74.5 \%)$ patients. Of the patients treated, $106(96.3 \%)$ had hepatocellular carcinomas, $3(2.7 \%)$ had 
Table 1 - Literature review of anterior hepatic transection for caudate lobectomy

\begin{tabular}{|c|c|c|c|c|c|}
\hline Reference & Year & No. & Diagnosis & Procedure & Comments \\
\hline Yamamoto et al (14) & 1992 & 1 & Hepatoma & ICL & AHT \\
\hline Shimada et al (15) & 1993 & 2 & Cholangiocarcinoma & $\begin{array}{c}\text { Anterior segmentectomy } \\
+\mathrm{CCL}\end{array}$ & AHT \\
\hline Sasada A et al (16) & 1998 & 2 & $\begin{array}{l}\text { Hemangioma } \\
\text { Metastatic liver tumor }\end{array}$ & $\mathrm{CCL}$ & AHT and RSA \\
\hline Asahara et al (17) & 1998 & 3 & Hepatocellular carcinoma & ICL & AHT \\
\hline Yamamoto et al (18) & 1999 & 5 & $\begin{array}{l}\text { Hepatocellular carcinoma } \\
\text { Metastatic liver tumor }\end{array}$ & ICL & AHT \\
\hline Peng et al (19) & 2003 & 6 & Hepatocellular carcinoma & CCL & AHT \\
\hline Yamamoto et al (20) & 2004 & 16 & Hepatocellular carcinoma & $\begin{array}{l}5 \mathrm{ICL}, 11 \mathrm{CCL}+ \\
\text { hepatectomy }\end{array}$ & AHT \\
\hline Hu et al (9) & 2005 & 13 & Hepatocellular carcinoma & ICL & \\
\hline Liu et al (21) & 2006 & 60 & Hepatocellular carcinoma & CCL & AHT \\
\hline Ishizawa et al (10) & 2007 & 2 & $\begin{array}{l}\text { Hepatocellular carcinoma } \\
\text { Metastatic liver tumor }\end{array}$ & ICL & AHT \\
\hline
\end{tabular}

RSA - right-sided approach; AHT - anterior hepatic transection; CCL - complete caudate lobectomy; ICL - isolated caudate lobectomy

metastatic caudate tumors, and $1(0.9 \%)$ had hemangioma. AHT was used in 108 (98.1\%) caudate resections, while AHT associated with a right-sided approach was performed in $2(1.8 \%)$ cases.

\section{DISCUSSION}

In the past, resection of the caudate lobe has been performed infrequently, partly due to the difficult dissection required and partly due to the perception of frequent early tumor involvement in the IVC or the portal vein. The caudate lobe can be the origin of primary liver tumors or the sole site of metastases to the liver. ${ }^{5,6}$

The paracaval portion of the caudate lobe is in front of the intrahepatic IVC just to the right of the Spiegel lobe and is closely associated with the right and middle hepatic veins. As a result of this unique anatomical location, caudate lobe resection is technically challenging, especially in cases of isolated caudectomy, because it is easy to damage the hilum or the bile duct in dissecting the caudate lobe's anterior. Additionally, an error in dissecting the posterior of the caudate lobe can cause uncontrolled bleeding from the inferior vena cava. The most difficult areas of the caudate lobe from which to remove tumors are the protruding portion and the portion near the inferior vena cava.

The key issues in performing a safe resection of the caudate lobe include meticulous dissection and maintaining control of the retrohepatic veins in the posterior area and exposing the branches joining the middle hepatic vein in the anterior area. The ultrasound dissector is a valuable tool to enable the precise transaction of the hepatic parenchyma and the denudation of venous branches.?

The choice of procedure is essential to the success of a caudate lobectomy. There are different procedures for performing a caudate lobectomy, but only three are effective: the anterior procedure, in which the hepatic parenchyma is resected from the middle line and the right and left porta hepatitis are pulled aside to expose the caudate lobe ${ }^{8}$ and right and left approaches to the caudate lobe. ${ }^{6}$

This review has shown that, when using AHT most caudate lobectomies are complete caudate lobectomies (75\%) due to hepatocellular carcinoma (96\%). Additionally, the anterior hepatic approach is a safe strategic alternative for isolated caudate lobectomies, ${ }^{9,10}$ but only $25 \%$ of the cases reviewed were submitted to this procedure. The combination of AHT and a right-sided approach accounted for less than $2 \%$ of cases, which proves that, for tumors located in the paracaval portion of the caudate lobe (segment IX), the best approach is an anterior transection of the liver parenchyma.

Caudate lobectomy is sometimes associated with a left or right hepatectomy; for instance, right hepatic trisectionectomy with caudate lobectomy and resection of Couinaud's hepatic segments $1,4,5,6,7$, and 8 is a surgical option usually indicated in advanced hilar cholangiocarcinoma, which mainly involves the right intrahepatic bile ducts in continuity with the left medial sectional bile duct. The relative volume resected in this hepatectomy averages $81 \%$ of the liver, which is an extensive liver resection. ${ }^{11}$

Opening the hepatic parenchyma overlying the caudate lobe exposes the major hepatic veins and the hilar plate to 




Figure 2 - Anterior approach after opening the interlobar plane and exposing the anterior surface of the paracaval portion and the hilar plate. The paracaval portion is detached from the hilar plate

direct view, facilitating control of venous bleeding and the interruption of the ascending paracaval portal branches along the hilar plate (Figures 2 and 3).

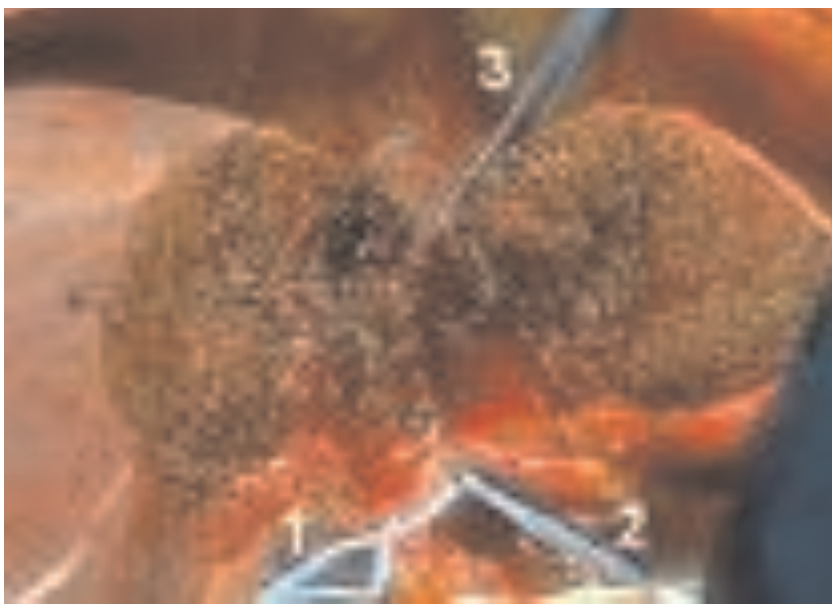

Figure 3 - Anterior approach to the liver for resection of the paracaval portion of the caudate lobe. Isolation of the portal pedicle $(1,2)$ and supra-hepatic inferior vena cava (3)

By separating the liver from the IVC, a safer transection can be carried out along the confines of the dorsal liver guided by the operator's left hand, which is placed behind the caudate lobe. There have been some reports of caudate lobe resections employing a combined right and left posterolateral approach. ${ }^{12,13}$ In such procedures, liver transaction is performed caudocranially. As a result, it is important to divide the ascending paracaval portal branches that originate from the craniodorsal aspects of the hilar plate, as well as to maintain control of the bleeding from the hepatic venous branches, especially when the tumor is large or when it is difficult to bend the liver because of cirrhosis. Using this method, liberation of the liver, securing the major hepatic veins, and complicated liver transaction all require a considerable amount of time, which is a significant shortcoming of these procedures. ${ }^{14}$

Possible congestion of the medial segment caused by interruption of the branches of the MHV along its left margin did not significantly impair the remaining hepatic function.

Anterior hepatic transection is a rarely required but safe and potentially curative surgical option for isolated resection of the caudate lobe, especially when cirrhosis is apparent. Additionally, in cases of metastatic liver carcinoma, it is possible to spare innocent hepatic parenchyma using this approach.

\section{CONCLUSION}

Anterior hepatic transection is recommended for tumors located in the paracaval portion of the caudate lobe (segment IX). It is usually a safe and potentially curative surgical option.

\section{ACKNOWLEDGEMENTS}

The authors thank Mr. Marcos Retzer for contributing the illustrations to this paper. 


\section{REFERENCES}

1. Kumon M. Anatomy of the caudate lobe with special reference to portal vein and bile duct. Acta Hepatol Jap. 1985;26:1193-9.

2. Makuuchi M, Yamamoto J, Takayama T, Kosuge T, Gunven P, Yamasaki $\mathrm{S}$, et al. Extrahepatic division of the right hepatic vein in hepatectomy. Hepato-gastroenterology. 1991;38:176-9.

3. Kosuge T, Yamamoto J, Takayama T, Shimada K, Yamasaki S, Makuuchi $\mathrm{M}$, et al. An isolated complete resection of the caudate lobe, including the paracaval portion, for hepatocellular carcinoma. Arch Surg. 1994;129:280-4.

4. Takayama T, Makuuchi M, Takayasu K, Le Thai B, Ohyama H, Yamasaki $\mathrm{S}$, et al. Resection after intraarterial chemotherapy of a hepatoblastoma originating in the caudate lobe. Surgery. 1990;107:231-5.

5. Chaib E, Ribeiro Jr MAF, Collet e Silva F, Saad WA, Ceconello I. Surgical approach for hepatic caudate lobectomy: review of 401 cases. J Am Coll Surg. 2007;204:118-27.

6. Chaib E, Ribeiro Jr MAF, Collet e Silva F, Saad WA, Ceconello I. Caudate lobectomy: tumor location, topographic classification and technique using right- and left-sided approaches to the liver. Am J Surg. 2008;196:245-51.

7. Malago M, Frilling A, Li j, Lang H Broelsch CE. Cholangiocellular carcinoma - the role of caudate resection and mesohepatectomy. HPB. 2008; 10:179-82.

8. Wen ZQ, Yan YQ, Yang JM, Wu MC. Precautions in caudate lobe resection: Report of 11 cases. World J Gastroenterol. 2008;14:2767-70.

9. Hu JX, Miao XY, Zhong DW, Dai WD, Liu W. Anterior approach for complete isolated caudate lobectomy. Hepato-gastroenterology. 2005;52:1641-4.

10. Ishizawa T, Hasegawa K, Ikeda M, Aoki T, Sano K, Imamura H, et al. Transhepatic approach for a small paracaval tumor in repeat resection. Dig Surg. 2007;24:409-12.

11. Nagino M, Kamiya J, Arai T, Nishio H, Ebata T, Nimura Y. Anatomic right hepatic trisectionectomy (extended right hepatectomy) with caudate lobectomy for hilar cholangiocarcinoma. Ann Surg. 2006;243:28-32.
12. Takayama T, Tanaka T, Higaki T, Katou K, Teshima Y, Makuuchi M. High dorsal resection of the liver. J Am Coll Surg. 1994;179:73-5.

13. Yanaga K, Matsumata T, Hayashi H,Shimada M, Urata K, Sugimachi K. Isolated hepatic caudate lobectomy. Surgery. 1994;115:757-61.

14. Yamamoto J, Takayama T, Kosuge T, Yoshida J, Shimada K, Yamasaki $\mathrm{S}$, et al. An isolated caudate lobectomy by the transhepatic approach for hepatocellular carcinoma in cirrhotic liver. Surgery. 1992;111:699-702.

15. Shimada M, Matsumata T, Maeda T, Yanaga K, Taketomi A, Sugimachi $\mathrm{K}$. Characteristics of hepatocellular carcinoma originating in the caudate lobe. Hepatology 1994;19:911-5.

16. Sasada A, Ataka K, Tsuchiya K, Yamagishi H, Maeda H, Okada M. Complete caudate lobectomy: Its definition, indications and surgical approaches. HPB Surgery. 1998;11:87-93.

17. Asahara T, Dohi K, Hino H, Nakahara H, Katayama K, Itamoto T, et al. Isolated caudate lobctomy by anterior approach for hepatocellular carcinoma originating in the paracaval portion of the caudate lobe. $\mathrm{J}$ Hepato-biliary Pancreatic Surg. 1998;5:416-21.

18. Yamamoto J, Kosuge T, Shimada K, Yamasaki S, Takayama T, Makuuchi M. Anterior transhepatic approach for isolated resection of the caudate lobe of the liver. World J Surg. 1999;23:97-101.

19. Peng SY, Li JT, Mou YP, Liu YB, Wu YL, Fang HQ, et al. Different approaches to caudate lobectomy with "curettage and aspiration" technique using a special instrument PMOD: a report of 76 cases. World J Gastroenterol. 2003;9:2169-73.

20. Yamamoto T, Kubo S, Shuto T, Ichikawa T, Ogawa M, Hai S, et al. Surgical strategy for hepatocellular carcinoma originating in the caudate lobe. Surgery. 2004;135:595-603.

21. Liu CL, Fan ST, Cheung ST, Lo CM, Ng IO, Wong J. Anterior approach versus conventional approach right hepatic resection for large hepatocellular carcinoma: a prospective randomized controlled study. Ann Surg. 2006;244:194-203. 
